\title{
REVIEW
}

\section{The ADMIT series - Issues in Inhalation Therapy. 6) Training tools for inhalation devices}

\section{*Federico Lavorinia, Mark L Levyb, Chris Corrigan`, Graham Crompton ${ }^{\text {, }}$, on behalf of the ADMIT Working Group}

\footnotetext{
a Department of Internal Medicine, Section of Immunoallergology, Respiratory Diseases and Cell Therapy, University of Florence, Italy

b Senior Clinical Research Fellow, Allergy \& Respiratory Research Group, Division of Community Health Sciences:GP Section, University of Edinburgh, UK Department of Asthma, Allergy \& Respiratory Science, King's College London School of Medicine, London, UK

d 14 Midmar Drive, Edinburgh, EH10 6BU, UK

e Members of the Aerosol Drug Management Improvement Team (ADMIT): Graham K Crompton, Edinburgh, UK, (Chair); Peter J Barnes, London, UK; Marielle Broeders, Nijmegen, The Netherlands; Lorenzo Corbetta, University of Florence, Italy; Chris Corrigan, London, UK; Richard Dekhuijzen, Nijmegen, The Netherlands; Jean Christophe Dubus, Marseille, France; Thomas Hausen, Essen, Germany; Meinhard Kneussl, Vienna, Austria; Federico Lavorini, University of Florence, Italy; Mark L Levy, Edinburgh, UK; Søren Pedersen, Kolding, Denmark; Antonio Ramalho de Almeida, Portugal; Nicholas Roche, Service de Pneumologie et Réanimation, Hôtel-Dieu, Paris, France; Joaquin Sanchis, Barcelona, Spain; José L Viejo, Hospital General Yagüe de Burgos, Spain; Walter Vincken, Universitair Ziekenhuis Brussel, Vrije Universiteit Brussel, Brussels, Belgium; Thomas Voshaar, Moers, Germany.
}

Received 22nd April 2010; revised version received 27th July 2010; accepted 4th August 2010; online 3rd November 2010

\begin{abstract}
Inhaled medications are the preferred therapies for patients with asthma and COPD, but their effectiveness is limited by the patient's ability to use the device properly, an issue often neglected when these medications are prescribed. Correct inhaler technique must be taught and learnt, and requires educational and motivational programs aimed at patients and healthcare providers alike. Written instructions alone are manifestly insufficient: education must include practical demonstration and periodic re-assessment and reeducation, since correct technique and motivation usually deteriorate with time. Several devices are available on the market, the purpose of which is to train patients to use inhalers correctly. They are often directed at particular devices or groups of devices and/or particular critical aspects of technique. This paper reviews the devices currently available for training patients in the correct use of both pressurised metered-dose inhalers (pMDIs) and dry powder inhalers (DPIs).
\end{abstract}

(C) 2010 Primary Care Respiratory Society UK. All rights reserved.

F Lavorini et al. Prim Care Resp J 2010; 19(4): 335-341

doi:10.4104/pcrj.2010.00065

Keywords In-Check-Dial, "2Tone” trainer, Turbutest, Inhalation Manager, Mag-Flo, SmartMist, pMDI, DPI.

\section{Contents}

Introduction

Training tools

1. "2Tone" Trainer

2. Turbutest

3. In-CheckDial

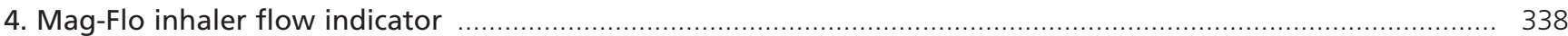

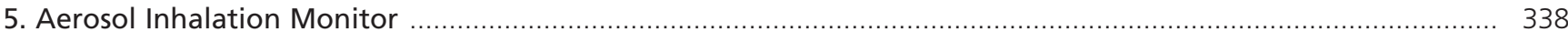

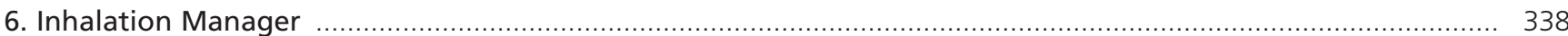

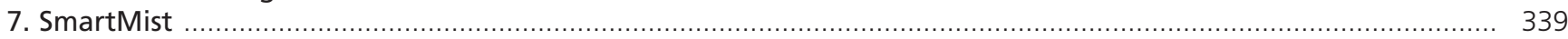

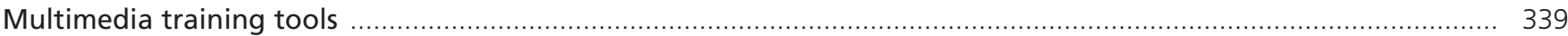

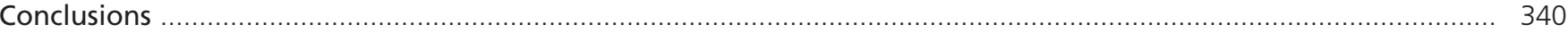

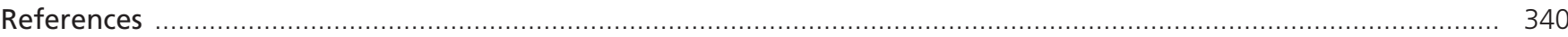

* Corresponding author: Dr Federico Lavorini, Department of Internal Medicine, Section of Immunoallergology, Respiratory Diseases and Cell Therapy, University of Florence, Viale Morgagni 85, 50134, Florence, Italy. Tel: +39-055-413183 Fax: +39-055-4223202 E-mail: f.lavorini@dac.unifi.it 


\section{Introduction}

Inhaled drugs play an important role in the treatment of asthma and chronic obstructive pulmonary disease (COPD), but their effectiveness and benefit/risk ratios are critically dependent upon delivery to their appropriate targets in the respiratory tract and, ideally, nowhere else. 'This requires that patients use delivery devices in a manner shown to optimise drug delivery. Otherwise, therapeutic benefit is reduced and the risk of adverse events increased - and both of these outcomes may in turn compromise compliance. ${ }^{2,3}$

The inhalation devices most commonly used are pressurised metered-dose inhalers (pMDIs) and dry-powder inhalers (DPIs). Both deliver a precise amount of drug in the form of aerosol particles of a size suitable for reaching the conducting airways, but only if used properly. Some patients cannot use particular devices because of factors such as age, disability and inadequate lung function. Even when patients can in theory use a particular device, errors of technique, some of which may critically compromise drug delivery, are well known to be frequent. ${ }^{2-5}$ With pMDIs, two of the most critical errors are failure to coordinate inhalation with actuation of the device, ${ }^{6}$ and inhaling the aerosol too quickly. ${ }^{7}$ With DPIs, successful aerosolisation of the dry powder depends on both the velocity and the acceleration of the inhalation manoevre, which in turn requires rapid and forceful inhalation. ${ }^{8}$ Problems are further increased when patients use more than one type of inhaler, resulting in confusion in terms of the different techniques required for each. ${ }^{9}$

Although coaching can improve the ability to use inhalers, it has been found that many patients revert to an incorrect inhalation technique within a short period. ${ }^{4,10}$ Thus, regular monitoring of inhalation techniques is necessary. Because the full potential of inhaled drugs cannot be achieved unless patients understand how to properly use inhaler devices, there is a need to train patients more effectively in following a proper sequence of inhalation steps in order to ensure maximum delivery of an inhaled drug to receptor sites in the lungs. Accordingly, there is a need for an inhalation training apparatus which will provide the patent and physician with a 'real-time', interactive representation of the inhalation process. Ideally, an inhalation training apparatus would provide visual feedback representing the actual distribution of inhaled aerosol in the lungs and show with reasonable accuracy the amount of aerosol delivered to the receptor sites. Such feedback would convey a conceptual understanding of the proper inhalation process, and thereby increase the likelihood that the patient would retain the correct technique. To date, various aids have appeared which are designed to help patients use inhalers correctly and efficiently. Some of these provide real-time, interactive sensory feedback of the patient's performance in various critical aspects of inhalation technique, which would seem optimal for "instilling" the correct technique into the patient's subconscious, but many do not.

In this article we review the tools for training patients in the correct use of both pMDIs and DPIs.

\section{Training tools}

\section{1. "2Tone" Metered-Dose Inhaler Training Device}

The "2Tone" Metered-Dose Inhaler Training Device, or "2Tone" Trainer, (Canday Medical Ltd, Newmarket, UK) is a training aid to help patients inhale aerosolised particles from pMDIs at a rate optimal for airways deposition. Most untrained patients inhale far too quickly from a pMDI and this is one error of pMDI technique which can critically reduce drug delivery. ${ }^{7}$ The training device looks similar to a pMDI but contains no medication or propellant (see Figure 1). All of the components are manufactured from medical grade plastics; it has been designed as a "single patient use" device for hygienic reasons, and should be cleaned at least once a month. The device is available in several European countries as well as in the USA. The patient information leaflet provided with this training aid encourages patients to practice using the device in the same way that they would use their pMDI. During use, the "2Tone" mimics what it is like to inhale through a pMDI and provides audible feedback on how fast air is being inhaled. ${ }^{7}$ A pair of sensitive reeds vibrate when air flows through them above a certain pre-determined speed, producing a single tone with optimal inhalation rates (30$60 \mathrm{l} / \mathrm{min})$, two tones if the rate is too fast $(>60 \mathrm{l} / \mathrm{min})$, and no noise at all if it is too slow. Patients are advised to obtain the onetone noise and thus become accustomed to the degree of inspiratory effort they need to make to achieve this rate through a pMDI. Compared with verbal training, the "2Tone" has been shown to produce sustained improvement in inhalation

Figure 1. "2Tone" Metered-Dose Inhaler Training Device.

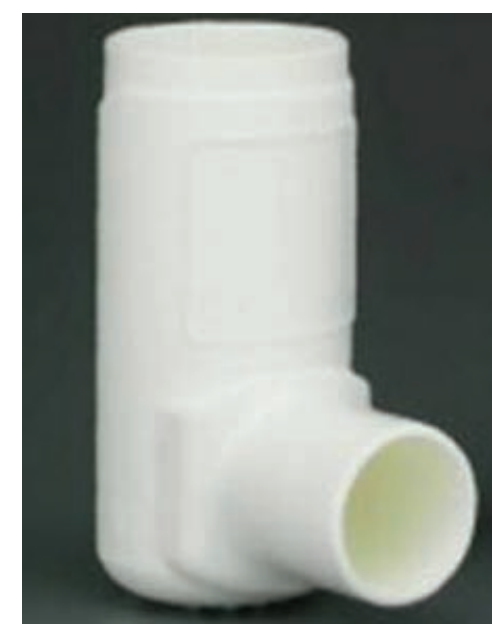




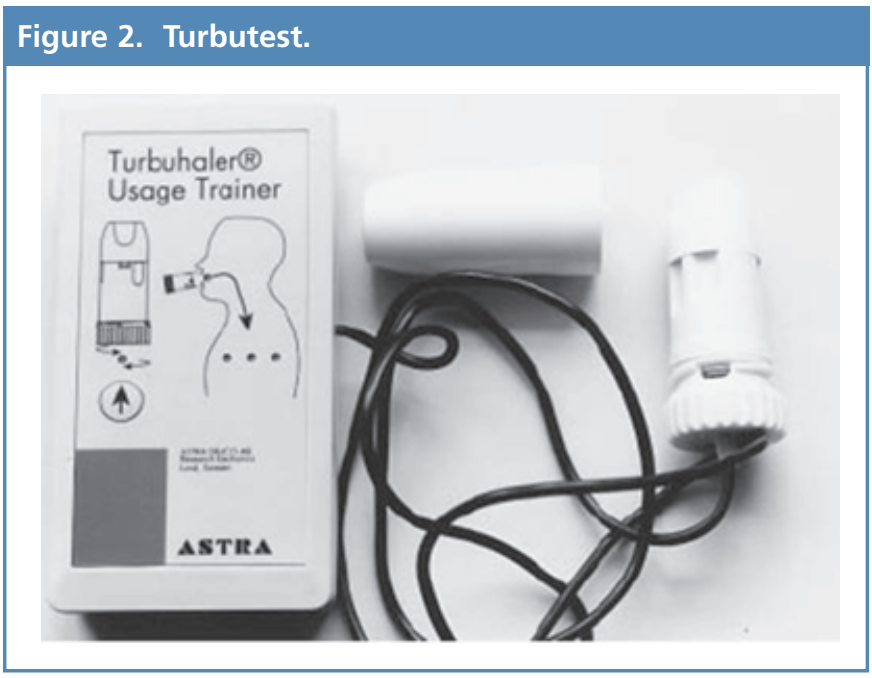

technique, lung function and quality of life in asthmatics using pMDIs, presumably because of better deposition of drug within the airways. ${ }^{7}$ Furthermore, improvements in asthma quality of life and lung function were obtained without changing the dose and without having to retrain the technique.? These findings highlight the potential of the "2Tone" to decrease costs as well as to improve health-care outcomes.

\section{Turbutest}

The Turbutest (Figure 2) is used to train patients in the correct use of the Turbohaler device. This device, available in several European countries, is a replica connected to an electronic sensor that measures peak inspiratory flow (PIF). ${ }^{11}$ The Turbutest grades PIF visually (3 lights $>60 \mathrm{l} / \mathrm{min}, 2$ lights $40-60 \mathrm{l} / \mathrm{min}$, 1 light $30-40$ $\mathrm{l} / \mathrm{min}$, and no lights $<30 \mathrm{l} / \mathrm{min}$ ). According to the manufacturer's specifications, patients must be able to light at least 2 lights in order to be able to generate a PIF sufficient to aerosolise the dry powder into particles of respirable size when using a Turbohaler. Inadequate PIF is one of the errors in DPI technique which may critically reduce drug delivery. In addition, the Turbutest also evaluates whether or not the patient has correctly performed the initial rotation of the base of the Turbohaler required to prime the inhaler; this is also a frequent and critical error in Turbohaler use. $^{5}$ In a large $(n=600)$ group of adult asthmatic patients, the Turbutest device revealed that 33\% of them generated inadequate PIF when using the Turbohaler, although none reported difficulty in using it beforehand."1

\section{In-CheckDial}

The In-CheckDial (Clement Clarke International Ltd, UK; see Figure 3 ) is a hand-held inspiratory airflow meter designed to identify the most appropriate inhaler device for patients, based on their ability to learn and achieve an optimal flow rate..$^{12-15}$ It accurately simulates the resistance encountered when using a number of different inhalers currently on the market, and measures the inspiratory flow rate achieved by the patient. Although designed primarily for DPIs, it can also measure
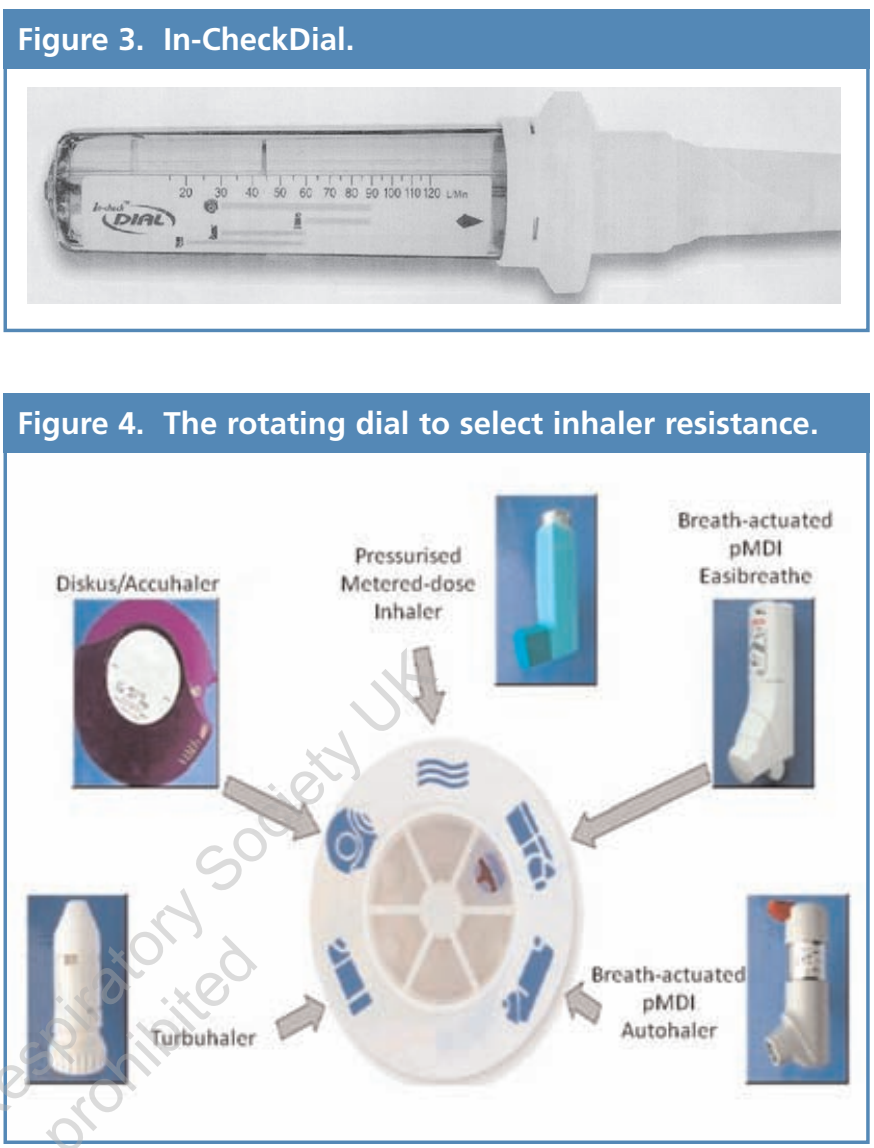

inspiratory flow through an inhaler with no resistance such as a pMDI, with or without a spacer, or a breath-actuated pMDI. The In-CheckDial is composed of two parts: an inspiratory flow meter and a rotating dial that selects different resistances (Figure 4). It is supplied with a sterilisable mouthpiece and a card showing optimal flow ranges for various devices. Patients unable to achieve a flow rate within the optimal range for a given inhaler should be provided with an alternative device. As mentioned, both the speed and the acceleration of the inspiratory manouevre when using a DPI critically affect the respirable dose. ${ }^{8,16}$ Although the In-CheckDial does not measure the speed of inhalation, Broeders and colleagues have shown that it correlates with PIF when patients use DPIs. ${ }^{14}$ In one study, ${ }^{12}$ the In-CheckDial showed that only a minority of COPD patients could generate a PIF of $60 \mathrm{l} / \mathrm{min}$ which is reported to be the minimum desirable flow rate when using the Turbohaler DPI. ${ }^{17}$ This finding is of importance since in vitro studies with the Turbohaler device ${ }^{18,19}$ have highlighted the high variability of the emitted dose below this inhalation rate. Although some clinical response may be obtained at inhalation rates between 30 and 60 $1 /$ min through the Turbohaler device, ${ }^{20}$ the response might be variable and in some cases slight. In another study, ${ }_{1}^{21}$ the InCheckDial detected that 14 out of 74 COPD patients (19\%) were not able to generate even the minimum $(30 \mathrm{l} / \mathrm{min}$ ) inhalation rate reported to be required for use of the Turbohaler device. 


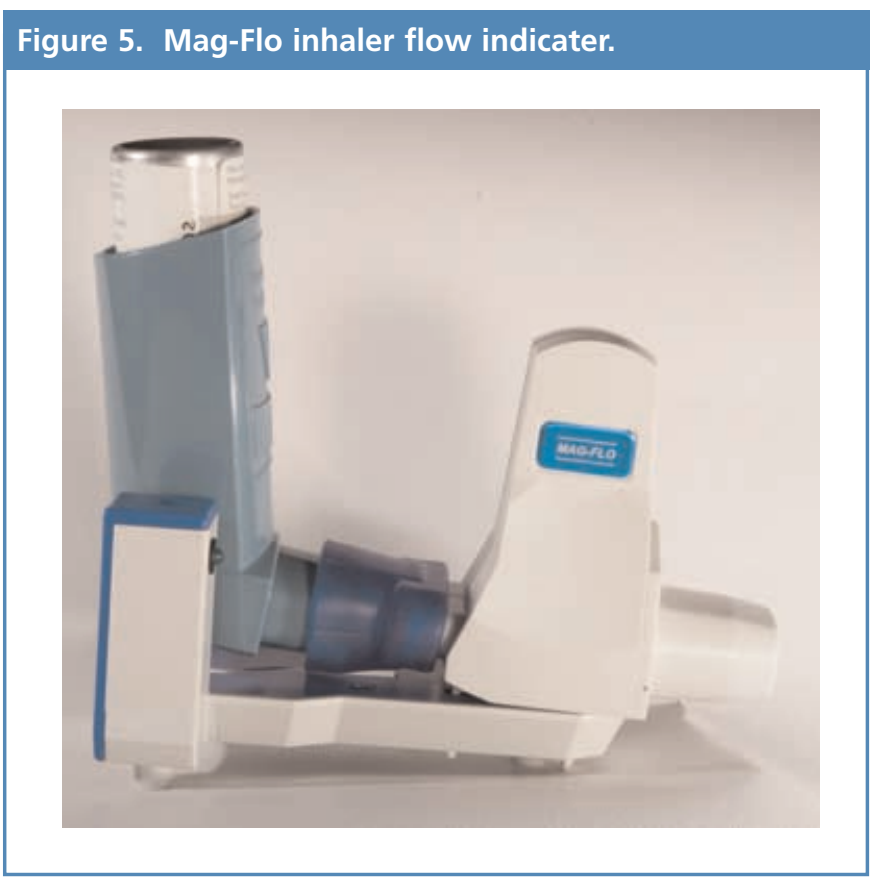

Similarly, in a group of young children apparently experienced with use of the Turbohaler device, the In-CheckDial revealed adequate PIF (>60 l/min) in only $68 \% .{ }^{15}$ In summary, the InCheckDial is a powerful tool that can greatly aid healthcare providers when prescribing inhalers for the first time and when checking technique. It provides real-time, objective feedback to patients and may improve drug delivery and compliance. ${ }^{12-15} \mathrm{It}$ can be used to check PIF in patients of all ages when using DPIS, whether new to the device or not.

\section{Mag-Flo inhaler flow indicator}

The Mag-Flo inhaler flow indicator (Fyne Dynamics Ltd, UK) evaluates patients' ability to use a variety of DPIs including the Turbohaler, the Diskus/Accuhaler, the Handihaler and the Novolizer devices.22 This inhalation aid (Figure 5) uses a magnetic flow sensor attached by an adaptor to the inhaler or training placebo. ${ }^{22}$ When the patient inhales correctly, the magnetic flow sensor is activated, switching on a battery powered green light, providing visual, real-time feedback to the patient as to inhalation speed. ${ }^{22}$ As far as we are aware, no published studies have evaluated the accuracy of this device in flow detection as well as its effect on patients' inhalation technique. However, it has the potential to teach patients using DPIs to inhale at an appropriate rate and pick out those who cannot.

\section{Aerosol Inhalation Monitor}

The Aerosol Inhalation Monitor (Vitalograph Ltd, Buckingham, UK) is an electronic, desktop pMDI trainer that measures patients' inspiratory flow rate and monitors coordination of inhalation with pressing the pMDI canister (Figure 6). It includes a placebo pMDI with a sensitive flowhead which detects flow once the patient starts inhaling. Feedback to the user is in the form of different coloured lights and an analogue needle gauge
Figure 6. Aerosol Inhalation Monitor.

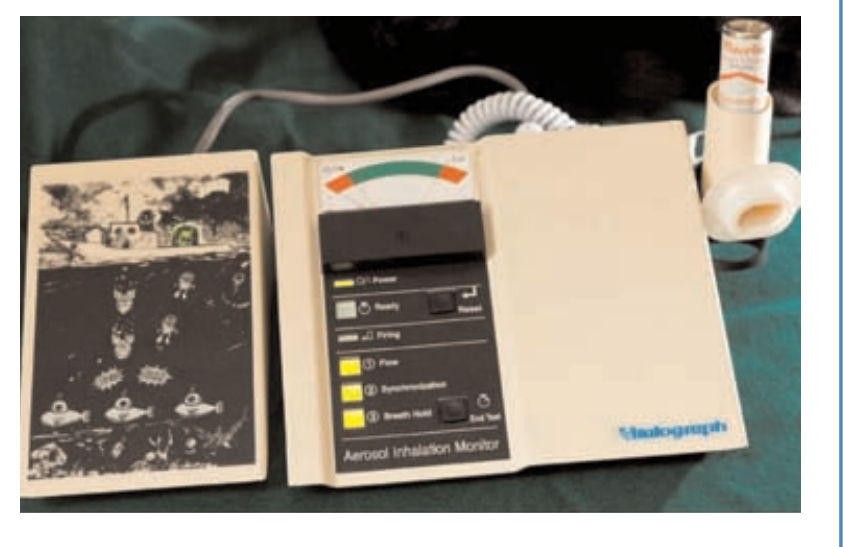

which indicates inspiratory flow rate, including a desired flow range..$^{23}$ During practice, the patient is asked to keep the needle gauge within the desired flow range. After completion of the full manouevre the device displays three coloured lights labelled "firing", "delivery" and "breath hold". A green light indicates that the patient performed the corresponding aspect of the inhalation correctly. Conversely, a red light indicates an incorrect technique. A secondary optional display provides an incentive device utilising several lights overlain with cartoon figures. ${ }^{23}$ Thus, the Aerosol Inhalation Monitor provides health educators and patients with both a visual and a quantitative assessment of patients' inhalation technique wih pMDIs. ${ }^{23}$ Furthermore, the device has been used in patients with acute asthma to verify correct inhalation technique and as a teaching aid with variable success. ${ }^{24}$ The Aerosol Inhalation Monitor has some disadvantages: feedback is not fully interactive and is not displayed across the entire time course of the manoevre, and performance parameters are not operator programmable.

\section{Inhalation Manager}

The Inhalation Manager is a user-friendly, computer-based measuring instrument which enables testing of the inhalatory capacity of patients using Turbohaler or Diskus/Accuhaler DPI devices and the Autohaler breath-actuated pMDI. It assesses the entire inspiratory manouevre and thus provides feedback to the patient and the health professional. In one study, ${ }^{25}$ the Inhalation Manager detected substandard inhalation technique in $1.5 \%$, $16.7 \%$ and $38.9 \%$ of adult patients up to 60 years old using the Autohaler, Diskus/Accuhaler and Turbohaler, respectively, rising to $1.5 \%, 31.5 \%$ and $66.1 \%$ in those aged over 60 years old. The Inhalation Manager also offers prediction of mass output and particle size distribution from any individual inspiratory manouevre through each of these inhaler devices, based on measurements from compatible flow profiles measured in the laboratory. ${ }^{8}$ Thus, the device offers the opportunity to hone inhaler technique precisely in individual patients at least with the currently covered devices. 


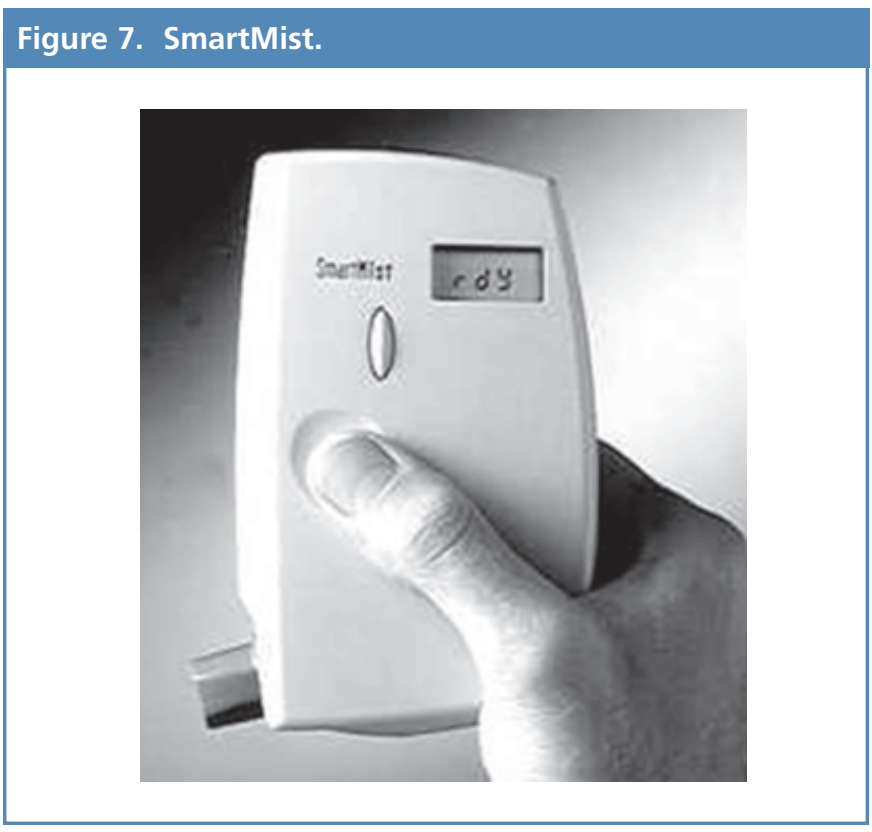

\section{SmartMist}

The SmartMist Respiratory Management System (Aradigm Corporation; Hayward, CA, US), is a hand-held breath-actuated, microprocessor-controlled, accessory for use with pMDIs. This electronic device, available in the USA, allows physicians to evaluate objectively patient adherence to treatment by recording the date and time of medication use..$^{26-29}$ In addition to serving as a reporting tool for compliance, the SmartMist records the inspiratory flow rate and the 'inspiratory firing volume' (the volume of air inhaled prior to actuation of the aerosol generation) at the time of delivery. Therefore, it can be used for assessing patients' inhalation technique, and, consequently, for training. The device prompts the patients to hold their breath for 10 seconds post-inhalation for optimum deposition. Furthermore, the electronic peak flow meter in the device can be used to assess and record the patient's response to therapy. ${ }^{29}$ The SmartMist (Figure 7) consists of a larger device that accommodates the pMDI and actuator with only the mouthpiece exposed. It contains a microprocessor that analyses an inspiratory profile and automatically actuates the pMDI when predefined conditions of inspiratory flow rate (25 to $60 \mathrm{~L} / \mathrm{min}$ ) and inspired volume ( 250 to $500 \mathrm{~mL}$ ) coincide, in order to minimise error in inhalation technique. ${ }^{29}$ It provides immediate guidance on technique with a flashing red light when inspiration is too rapid (> $60 \mathrm{~L} / \mathrm{min}$ ), a solid green light when the inspiratory flow is appropriate (25 to $60 \mathrm{~L} / \mathrm{min}$ ), or no light indicating insufficient inspiratory flow (<25 L/min). Using red and green indicator lights to provide instant feedback on proper inhalation technique, the SmartMist guides patients to breathe slowly and evenly, and automatically dispenses drug when the desired flow rate is established. Information on inhalation technique and records data on drug administration can be downloaded with the accompanying cable onto a personal computer. The data can be viewed and printed as a list of events or a series of graphs. The validity and reliability of the SmartMist have been well characterised, ${ }^{30}$ and clinical studies performed in asthma patients have shown that the SmartMist improves inhalation technique and diary accuracy for both medication use and pulmonary function values. ${ }^{31}$

\section{Multimedia training tools}

Recorded materials (videotape and digital media such as DVDs) and web-based mutimedia information systems incorporating video clips showing demonstration of correct use of pMDls and DPIs ${ }^{32-34}$ are frequently used for training patients. These information systems offer an attractive alternative option for teaching or reinforcing correct inhaler use, particularly for children and other people who cannot read the information in the manufacturer's patient information leaflet. Multimedia educational software delivers information to a laptop or desktop computer screen using a range of visual and auditory forms, including animation, video, voice-over, and sound effect. The interactive capabilities of such programs and their potential to store users' responses can be harnessed to provide personalised information in engaging forms such as games or quizzes. In addition, using multimedia to deliver health information has practical advantages: electronic information stored on portable disk, computer disk or on a Web page is easy to share across health care settings, and takes up much less shelf space than paper-based methods. Recently, the Aerosol Management Improvement Team (ADMIT) provided its web platform ${ }^{34}$ with interactive tools on how to use the most popular inhalation devices throughout the world correctly. Using multimedia may also be more effective than print-based information, as the need for some active input from the recipient is claimed to make learning both easier and more enjoyable than with conventional methods. ${ }^{35} \mathrm{~A}$ degree of choice can be offered as to how information is presented (e.g. language, age, gender, ethnicity). This could increase the acceptability and personal relevance of the information, and help inhaler users to feel more involved in their own health care. Savage and Goodyer ${ }^{36}$ compared, in asthma patients, the effects of brief exposure to standard information on correct pMDI use, given by the manufacturer's patient information leaflet and by a multimedia program. They found that both information methods induced similar improvements in global inhaler technique ratings in around a third of patients. There were differences between the two information-giving methods in terms of engaging attention, and in the observed changes in specific aspects of technique. However, unlike paper leaflets, the information provided by multimedia takes up little space, is easy to share, and the technology required is well established and relatively low cost. ${ }^{36}$ 


\section{Conclusion}

Most professionals would accept that no inhaled drug can effectively treat asthma or COPD unless it reaches the airways, so that using delivery devices to achieve this with maximum efficiency is the cornerstone of management of these diseases. Although guidelines acknowledge that inhalers should be prescribed only after patients have been trained to use them properly and have demonstrated this ability, 37,38 many studies ${ }^{4,5}$ suggest that this critical aspect of patient care is poorly addressed. Yet health professionals now have a number of tools available with which to hone perfect inhaler technique in each individual patient. Incorrect or inefficient inhaler usage may be a direct consequence of poor instruction, ${ }^{39}$ but this is improved (albeit temporarily) by training. ${ }^{40,41}$ The quality of this training is of paramount importance. The manufacturer's instruction sheet alone is ineffective in achieving correct technique. ${ }^{42-44}$ Patients with asthma or COPD using an inhaler for the first time are more likely to demonstrate the correct technique after receiving verbal instruction than after reading the manufacturer's leaflet. ${ }^{44}$ Instruction provided in groups or by video can also be as effective as one-to-one instruction in improving technique. ${ }^{45}$

As we have stressed in this article, there is now abundant scope for excellent practical instruction with various aids. Inhaler technique education is best delivered by verbal instructions and physical demonstration of the technique by a skilled educator, either face to face or by video.46.47 Demonstrating the steps can also help overcome language barriers. ${ }^{48}$ What is still missing perhaps is the required time and organisation. Inhaler technique must be rechecked and education must be reinforced regularly in order to maintain correct technique, since inhaler technique deteriorates again after education. ${ }^{4,5}$ Surveys continue to suggest, however, that substantial proportions of patients prescribed inhalers receive no verbal instruction at all, ${ }^{43,49}$ or a brief, one-off session. ${ }^{50}$ Follow-up is important when one considers that as early as three days after successful instruction, more than a third of patients may no longer use their DPI correctly, ${ }^{43}$ but they fare much better with repetition. ${ }^{51}$ Finally, "going through the motions" of inhaler training, even if repeated, although essential is not always enough. The health professional must "go the extra mile" to perfect inhaler technique and eliminate critical errors that can vastly reduce inhaler performance. Training devices to facilitate this are easy to use and in some cases measure patients' inspiratory flow, so that good technique can be learned quickly, even by children, and checked objectively.

\section{Conflict of interest declaration}

$\mathrm{F}$ Lavorini has been reimbursed for attending conferences and/or giving talks by
Menarini Industrie Farmaceutiche, AstraZeneca and Pfizer. He serves as a consultant to Meda AB.

ML Levy has been reimbursed for attending conferences and/or giving talks by, and has acted as a consultant for, AstraZeneca, GlaxoSmithKline, Ivax, 3M, Novartis, MSD, Altana, Meda AB, Trinity Chiesi, Boehringer Ingelheim, Ranbaxy, Innovata Biomedica and Schering Plough. He has received research grants from Ivax, Boehringer Ingelheim, GlaxoSmithKline, Schering Plough and AstraZeneca. He is the Editor-in-Chief of the PCRJ, but was not involved in the editorial review of, nor the decision to publish, this article.

$C$ Corrigan has been reimbursed for attending conferences and/or giving talks by Schering- Plough, Allergy Therapeutics, Med AB, UCB Pharma. His department has received research grants from GlaxoSmithKline, Novartis, ALK-Abello, Allergy Therapeutics. He has acted as a consultant for Meda AB, GlaxoSmithKline, MSD, Allergopharma, Joachim Ganzer AB

$\mathrm{G}$ Crompton has given talks and acted as a consultant forMEDA AB.

Conflicts of interest for all ADMIT members are listed at the end of the first paper in this series - see Dekhuijzen et al., Prim Care Resp J 2007;16(6):341-8.

\section{References}

1. Pauwels R, Newman S, Borgström L. Airway deposition and airway effects of antiasthma drugs delivered from metered-dose inhalers. Eur Respir J 1997; 10:2127-38.

2. McFadden ER. Improper patient techniques with metered dose inhalers: clinical consequences and solutions to misuse. J Allergy Clin Immunol 1995;96:278-83. http://dx.doi.org/10.1016/S0091-6749(95)70206-7

3. Crompton GK. Problems patients have using pressurised aerosol inhalers. Eur $J$ Respir Dis 1982;63(Suppl.119):101-04.

4. Crompton GK, Barnes PJ, Broeders M, et al. The need to improve inhalation technique in Europe: a report from the Aerosol Drug Management Improvement Team. Respir Med 2006;100:1479-94. http://dx.doi.org/ 10.1016/j.rmed.2006.01.008

Lavorini F, Magnan A, Dubus JC, et al. Effect of incorrect use of dry powder inhalers on management of patients with asthma and COPD. Respir Med 2008;102:593-604. http://dx.doi.org/10.1016/j.rmed.2007.11.003

6. Newman SP, Weisz AW, Talaee N, Clarke SW Improvement of drug delivery with a breath actuated pressurised aerosol for patients with poor inhaler technique. Thorax 1991;46:712-16. http://dx.doi.org/10.1136/thx.46.10.712

7. Al-Showair RA, Pearson SB, Chrystyn H. The potential of a 2 Tone Trainer to help patients use their metered-dose inhalers. Chest 2007;131:1776-82. http://dx.doi.org/10.1378/chest.06-2765

8. Kamin WES, Genz T, Roeder $\mathrm{S}$, et al. Mass output and particle size distribution of glucocorticosteroids emitted from different inhalation devices depending on various inspiratory parameters. J Aerosol Med 2002;15:65-73. http://dx.doi.org/10.1089/08942680252908593

9. van der Palen J, Klein JJ, van Herwaarden CL, Zielhuis GA, Seydel ER. Multiple inhalers confuse asthma patients. Eur Respir J 1999;14:1034-7.

10. Duerden M, Price D. Inhalers. Education and training needs. Current Ther 2002;21-29.

11. Branco Ferriera M, Santos A, Clode MH, Palma Carlos AG. Turbutest in the training of asthmatic Turbuhaler users. Allergy 1999;54:375-9. http://dx.doi.org/10.1034/j.1398-9995.1999.00969.x

12. Van der Palen J. Peak inspiratory flow through Diskus and Turbuhaler, measured by means of a peak inspiratory flow meter (In-Check DIALs). Respir Med 2003;97:285-9. http://dx.doi.org/10.1053/rmed.2003.1289

13. Chrystyn $\mathrm{H}$. Is inhalation rate important for a dry powder inhaler? Using the InCheck Dial to identify these rates. Respir Med 2003;97:181-7. http://dx.doi.org/10.1053/rmed.2003.1351

14. Broeders MEAC, Molema J, Vermue NA, Folgering HTM. In Check Dial: accuracy for Diskus and Turbuhaler. Inter J Pharm 2003;252:275-80.

15. Amirav I, Newhouse MT, Mansour Y. Measurement of peak inspiratory flow with In-Check Dial device to simulate low-resistance (Diskus) and high- 
resistance (Turbohaler) dry powder inhalers in children with asthma. Pediatr Pulmonol 2005;39:447-51. http://dx.doi.org/10.1002/ppul.20180

16. Everard ML, Devadason SG, Le Soeuf PN. Flow early in the inspiratory manoeuvre affects the aerosol particle size distribution from a Turbuhaler. Respir Med 1997;91:624-8. http://dx.doi.org/10.1016/S0954-6111(97)90009-3

17. Borgstrom L, Bondesson E, Moren F, Trofust E, Newman SP. Lung deposition of budesonide inhaled via Turbuhaler. A comparison with terbutaline sulfate in normal subjects. Eur Respir J 1994;7:69-73. http://dx.doi.org/10.1183/ 09031936.94 .07010069

18. Malton A, Sumby BS, Dandiker Y. A comparison of in-vito drug delivery from salbutamol Diskus and terbutaline Turbuhaler inhalers. J PharmMed 1996;6:3545.

19. Palander A, Mattila T, Karhu M, Muttonen E. In-vitro comparison of three salbutamol-containing multidose dry powder inhalers. Clin Drug Invest 2000;20:25-33. http://dx.doi.org/10.2165/00044011-200020010-00004

20. Pedersen $S$, Hansen OR, Fuglsang $G$. Influence of inspiratory flow-rate upon the effect of a Turbuhaler. Arch Dis Child 1990;65:308-10. http://dx.doi.org/10.1136/adc.65.3.308

21. Nsour W, Alldred A, Corrado OJ, Chrystyn H. Measurement of peak inspiration rates with an In-Check meter to identify an elderly patient's ability to use a Turbuhaler. Respir Med 2001;95:965-8. http://dx.doi.org/10.1053/ rmed.2001.1190

22. www.fyne-dynamics.com

23. Skaer TL, Wilson CB, Sclar DA, et al. Metered-dose inhaler technique and quality of life with airways disease: assessing the value of the Vitalograph in educational intervention. J Int Med Res 1996;24:369-75.

24. Shrestha $M$, Parupia $H$, Andrews $B$, et al. Metered-dose inhaler technique of patients in an urban ED: prevalence of incorrect technique and attempt at education. Am J Emerg Med 1996;14:380-4. http://dx.doi.org/10.1016/507356757(96)90054-6

25. Kamin WES, Genz T, Roeder S, et al. The Inhalation Manager: A new computerbased Device to assess inhalation technique and drug delivery to the patient. J Aerosol Med 2003;16:21-9. http://dx.doi.org/10.1089/089426803764928329

26. Bender B, Milgrom H, Rand C, Ackerson L. Psychological factors associated with medication nonadherence in asthmatic children. J Asthma 1998;35:347-53. http://dx.doi.org/10.3109/02770909809075667

27. Wamboldt FS, Bender BG, O'Connor SL, et al. Reliability of the model MC$311 \mathrm{MDI}$ chronolog. J Allergy Clin Immunol 1999;104:53-5. http://dx.doi.org/10.1016/S0091-6749(99)70113-2

28. Bender B, Wamboldt FS, O'Connor SL, et al. Measurement of children's asthma medication adherence by self report, mother report, canister weight, and Doser CT. Ann Allergy Asthma Immunol 2000;85:416-21. http://dx.doi.org/10.1016/\$1081-1206(10)62557-4

29. Gonda I, Schuster JA, Rubsamen RM, Lloyd P, Cipolla D, Farr SJ. Inhalation delivery systems with compliance and disease management capabilities. J Control Release 1998;53:269-74. http://dx.doi.org/10.1016/501683659(97)00260-5

30. Julius SM, Sherman JM, Hendeles L. Accuracy of three electronic monitors for metered-dose inhalers. Chest 2002;121:871-6. http://dx.doi.org/ 10.1378/chest.121.3.871

31. Boushey $\mathrm{H}$, Janson $\mathrm{S}$, Wong $\mathrm{H}$, et al. Effects of an automated delivery device oncorrectness of $\mathrm{MDI}$ use over 2 weeks in asthmatic adults. Am J Respir Crit Care Med 1997;155:A893.

32. http://www.asthma.org.uk
33. www.NationalAsthma.org.au

34. www.admit-online.info

35. Jelovsek F. Learning principles as applied to computer-assisted instruction. Computing 1993;10(3):165-71

36. Savage I, Goodyer L. Providing information on metered dose inhaler technique: is multimedia as effective as print? Fam Pract 2003;20:552-7. http://dx.doi.org/10.1093/fampra/cmg510

37. British Thoracic Society Scottish Intercollegiate Guidelines Network. British Guideline on the Management of Asthma. Thorax 2008;63(suppl.4):1-121.

38. Global Initiative for Asthma. Global strategy for asthma management and prevention. http://www.ginaasthma.com. Updated December 2007

39. Virchow JC, Crompton GK, Dal Negro R, et al. Importance of inhaler device in the management of airway disease. Respir Med 2008;102:10-19. http://dx.doi.org/10.1016/j.rmed.2007.07.031

40. Goren A, Noviski N, Avital A, et al. Assessment of the ability of young children to use a powder inhaler device (Turbuhaler). Pediatr Pulmonol 1994;18:77-80. http://dx.doi.org/10.1002/ppul.1950180204

41. Broeders ME, Molema J, Hop WC, et al. Inhalation profiles in asthmatics and COPD patients: reproducibility and effect of instruction. I Aerosol Med 2003;16:131-41. http://dx.doi.org/10.1089/089426803321919898

42. Ronmark $E$, Jogi $R$, Lindqvist $A$, et al. Correct use of three powder inhalers: comparison between Diskus, Turbuhaler, and Easyhaler. J Asthma 2005;42:173-8.

43. Nimmo CJ, Chen DN, Martinusen SM, Ustad TL, Ostrow DN. Assessment of patient acceptance and inhalation technique of a pressurized aerosol inhaler and two breath-actuated devices. Ann Pharmacother 1993;27:922-7.

44. Serra-Batlles J, Plaza V, Badiola C, Morejon E. Patient perception and acceptability of multidose dry powder inhalers: a randomized crossover comparison of Diskus/Accuhaler with Turbuhaler. J Aerosol Med 2002;15:5964. http://dx.doi.org/10.1089/08942680252908584

45. van der Palen J, Klein JJ, Kerkhoff $A H$, van Herwaarden $C L$, Seydel ER. Evaluation of the long-term effectiveness of three instruction modes for inhaling medicines. Patient Educ Couns 1997;32:587-95.

45. Gracia-Antequera M, Morales Suarez-Varela MM. An intervention to improve the inhalatory technique of children and adolescents with asthma. Allergol Immunopathol 1999;27:255-60. http://dx.doi.org/10.1016/S0738-3991(97)00100-6

46. Basheti IA, Reddel HK, Armour CL, Bosnic-Anticevich SZ. Counseling about Turbuhaler technique: needs assessment and effective strategies for community pharmacists. Respir Care 2005;50:617-23.

47. Basheti IA, Armour CL, Bosnic-Anticevich SZ, Reddel HK. Evaluation of a novel educational strategy, including inhaler based reminder labels, to improve asthma inhaler technique. Patient Educ Couns 2008;72:26-33. http://dx.doi.org/10.1016/j.pec.2008.01.014

48. Goodyer L, Savage I and Dikmen Z. Inhaler technique in Turkish people with poor English: a case of information discrimination? Pharmacy World \& Science 2006;28:107-14. http://dx.doi.org/10.1007/s11096-006-9019-5

49. Epstein SW, Manning CPR, Ashley MJ, et al. Survey of the clinical use of pressurized aerosol inhalers. Can Med Assoc J 1979;120:813-16.

50. Melani AS, Zanchetta D, Barbato N, et al. Inhalation technique and variables associated with misuse of conventional metered-dose inhalers and newer dry powder inhalers in experienced adults. Ann Allergy Asthma Immunol 2004;93:439-46. http://dx.doi.org/10.1016/S1081-1206(10)61410-X

51. De Boeck K, Alifier M, Warnier G. Is the correct use of a dry powder inhaler (Turbohaler) age dependent? J Allergy Clin Immunol 1999;103:763-7. http://dx.doi.org/10.1016/S0091-6749(99)70417-3 